\title{
Improving management of paracetamol overdose: a software solution
}

\author{
Michael Stewart, ${ }^{1}$ Alison Robinson, ${ }^{2}$ Andy Curran ${ }^{1}$
}

${ }^{1}$ Emergency Department, Lancashire Teaching Hospitals NHS Foundation Trust, Preston, UK

${ }^{2}$ Emergency Department, Royal Blackburn Hospital, Blackburn, UK

\section{Correspondence to}

Dr Michael Stewart, Emergency Department, Lancashire Teaching Hospitals NHS Foundation Trust, Preston PR2 9HT, UK;

Michael@gradmedic.org

Received 8 September 2014 Accepted 21 October 2014

CrossMark

To cite: Stewart $\mathrm{M}$,

Robinson A, Curran A. BMJ

Innov 2015:1:22-24.

\begin{abstract}
Objective Paracetamol overdose is a common presentation to UK emergency departments, and national audits consistently identify shortfalls in the management of these patients. This study assesses the potential of a web-based computer application to improve the assessment and treatment of these patients.

Methods A retrospective cohort of patients was identified and their actual management and that advised by the software were assessed against current guidelines.
\end{abstract}

Results The application gave correct advice in all cases, significantly outperforming both actual treatment when the patients originally presented, and national performance based on previous College of Emergency Medicine audits.

Conclusions Advice from custom-written software outperforms actual treatment of patients presenting after paracetamol overdose.

\section{INTRODUCTION}

Paracetamol is the most common drug taken in overdose in the UK, and is estimated to cause up to 200 deaths/year. ${ }^{12}$ Evidence-based guidelines for the management of paracetamol overdose are available from the National Poisons Information Service (NPIS). Audits have shown that the management of these cases is often suboptimal-most recently a College of Emergency Medicine (CEM) audit found management was correct in only $83 \%$ of cases. ${ }^{34}$

We have developed an application that runs on web browsers, that takes details about a paracetamol overdose and provides advice regarding blood tests and use of $N$-acetylcysteine. ${ }^{5}$

The aim of this study was to evaluate the performance of the computer application, comparing it to the actual treatment provided to a historical cohort of patients who presented after an overdose of paracetamol.

\section{METHODS}

An initial sample size calculation indicated that 160 records would be required to give $80 \%$ power to detect a $10 \%$ difference in correct management rate between the application and actual management.

The departmental computer system (Quadramed QCPR) was searched for patients presenting between August 2010 and February 2011 coded as 'Overdose' or 'Poisoning'. Notes were reviewed and those for adults who had taken an overdose of paracetamol were included. A cohort diagram for the cases screened is given in figure 1. Key details of the overdose and treatment were recorded on a proforma.

The data from each case was entered into the application and the recommended management was recorded. Two authors independently reviewed the actual management and that recommended by the application, and compared these with the NPIS guidelines current at that time. Any discrepancies were discussed and a consensus decision was reached. The proportion of patients treated correctly at the time and in theory by the software were compared with McNemars test. The accuracy of the actual treatment and software-recommended treatment were compared to national figures using $\chi^{2}$ goodness of fit.

\section{RESULTS}

Six hundred and sixty-one cases were coded as overdose or poisoning in the Misys system. Two hundred and four of these were of paracetamol; on review of the notes there was incomplete data for 
Database search

$n=661$

Exclude non-paracetamol overdose and children

457 cases excluded

$n=204$

Exclude cases with incomplete information

41 cases excluded

$n=163$

Of these 163 :

- 7 staggered $(4.3 \%)$

- 37 required treatment $(22 \%)$

Figure 1 Flow chart of cases included in the analysis.

41 patients, leaving 163 records to be analysed. Thirty-six patients (22\%) required treatment and there were 7 (4.3\%) staggered overdoses, both lower than national median figures in $2008 .^{4}$

Details for the patients given the correct treatment at the time of original presentation and by the software are given in table 1.

The application outperformed both local practice and national comparison figures $(\mathrm{p}<0.001)$.

\section{DISCUSSION}

Computers are widely used in emergency departments to provide access to Departmental, Trust and National clinical guidelines, as well as to calculate drug dosages and clinical risk scores. ${ }^{67}$ Studies assessing their role in aiding patient assessment and management are emerging, but these systems are not yet in widespread use. ${ }^{89}$

The guidelines for the management of paracetamol overdose are relatively complex, more so prior to the simplifications introduced in 2012. When presented as a flow chart, there were 16 branch points where a decision had to be made as to which treatment path to follow. ${ }^{10}$ Many of these decisions required numerical calculations to be performed. An error in any one calculation or decision has the potential to lead to incorrect treatment and avoidable harm to a patient. However, the fact that they can be represented in a flow chart made it clear that they could be coded into computer software.

The ideal format for this application would be widely available, independent of computer platform, and handle patient details securely. A web page running Javascript was used as it runs on all modern browsers, and the code executes on the local computer-therefore no information is transmitted to the server hosting the code, so there is no opportunity for breach of confidentiality or transfer of data remotely.

Table 1 Summary of results

\begin{tabular}{llll}
\hline & Local results & Software & CEM audit \\
\hline Total number of cases & 163 & & \\
Of which correctly managed & $129(79.1 \%)$ & & $(100 \%)$ \\
Staggered overdose or present $>8 \mathrm{~h}$ after overdose & $28(17 \%$ of total) & & $(8 \%$ of total) \\
Of which correctly managed & $11(39 \%)$ & $28(100 \%)$ & $(2 \%)$ \\
\hline
\end{tabular}

CEM, College of Emergency Medicine. 
While the guidelines in use at the time have been superseded, the most common situations in which an error was made (presentation more than $8 \mathrm{~h}$ after overdose or after staggered overdose) still exist in the new recommendations. An updated application is being evaluated prospectively and early indicators are that it is still more accurate in guiding the management of patients presenting after paracetamol overdose than clinicians using written guidelines.

The study used a historical cohort and so can only be as accurate as the information found in the notes.

This study does not differentiate between incorrect management due to lack of knowledge and that due to external pressures; if a patient is not seen until several hours after arrival due to pressure of numbers in the department their treatment might be delayed despite an immediate decision being made once they are assessed. There may still be a positive impact from the application if it were to be used at triage to identify patients who need to be reviewed earlier or triaged in a higher category.

\section{CONCLUSIONS}

Simple computer software, that can be run as a webbased application, gave advice consistent with guidelines in every case tested. Further work is needed to see if this continues to apply in day-to-day clinical use.

Contributors MS proposed the study; all authors were involved in data collection and analysis and in writing the paper. MS acts as the guarantor.
Competing interests None.

Ethics approval Ethics approval was provided by the National Research Ethics Committee North West.

Provenance and peer review Not commissioned; externally peer reviewed.

\section{REFERENCES}

1 Fagan E, Wanna G. Reducing paracetamol overdoses. BMJ 1996;313:1417-8.

2 Atcha Z. Paracetamol related deaths in England and Wales, 1993-1997 (Office for National Statistics). Health Stat Q 2000;1:5-9.

3 Hulbert DC, Bray GP, Beckett MW. The management of paracetamol poisoning by junior doctors. J Accid Emerg Med 1995;12:66-7.

4 http://www.collemergencymed.ac.uk/CEM/Clinical\% 20Effectiveness $\% 20$ Committee/CEC $\% 20$ Standards $\% 20$ and $\%$ 20Audit/Clinical\%20Audit/Previous\%20Audits/default.asp (accessed Jan 2013).

5 http://www.gradmedic.org/paracetamol (accessed May 2014).

6 http://www.crashcall.net (accessed May 2014).

7 http://www.mdcalc.com (accessed May 2014).

8 Cooper JG, West RM, Clamp SE, et al. Does computer-aided clinical decision support improve the management of acute abdominal pain? A systematic review. Emerg Med J 2011;28: 553-7.

9 Fitzgerald M, Cameron P, Mackenzie C, et al. Trauma resuscitation errors and computer-assisted decision support. Arch Surg 2011;146:218-25.

10 Wallace CI, Dargan PI, Jones AL. Paracetamol overdose: an evidence based flowchart to guide management. Emerg Med J 2002;19:202-5. 